\title{
Auf der Suche nach der effektiven Adipositastherapie
}

\section{Liraglutid, ein Analogon des Gluca- gon-like-Peptide-1 (GLP-1), führt dosis- abhängig im Verlauf von 20 Wochen zu einer Gewichtsabnahme zwischen 4,8 und $7,2 \mathrm{~kg}$, ohne dass wesent- liche Nebenwirkungen auftreten.}

- In den vergangenen 20 Jahren hat die Adipositas in den westlichen Industrieländern explosionsartig zugenommen. Mittlerweile müssen über 50\% aller Erwachsenen in Europa als übergewichtig bezeichnet werden. Dabei handelt es sich keinesfalls nur um ein kosmetisches Problem, da die Adipositas der wichtigste Grundstein für Diabetes und Hyertonie bildet, die ihrerseits zur Arteriosklerose führen.

Nachdem diätetische Maßnahmen langfristig kaum zum Erfolg führen, sucht die Pharmaindustrie seit Jahren fieberhaft nach Substanzen, die zur Adipositastherapie verwendet werden können. Jüngstes Kind aus dieser Rei- he ist Liraglutid, ein Analogon des Glucagon-like-Peptide-1 (GLP-1), eines Inkretinhormons, das im oberen Dünndarm vorkommt. Während natives GLP-1 nur eine Halbwertszeit von ein bis zwei Minuten hat, ist es durch molekulare Modifikationen mit Liraglutid gelungen, die Halbwertszeit nach einer einzigen subkutanen Injektion auf 13 Stunden zu verlängern.

Liraglutid wurde als Behandlungsoption für den Diabetes mellitus Typ 2 entwickelt und zugelassen. Erste präklinische Untersuchungen zeigten, dass es neben einer Verbesserung der diabetischen Stoffwechsellage vor allem zu einer deutlichen Gewichtsabnahme der Probanden kam. Daher hat man nun in einer placebokontrollierten Doppelblindstudie 564 Patienten im Alter zwischen 18 und 65 Jahren mit einem Bodymassindex zwischen 30 und 40 $\mathrm{kg} / \mathrm{m}^{2}$ entweder mit Orlistat oder Liraglutid bzw. Placebo behandelt.

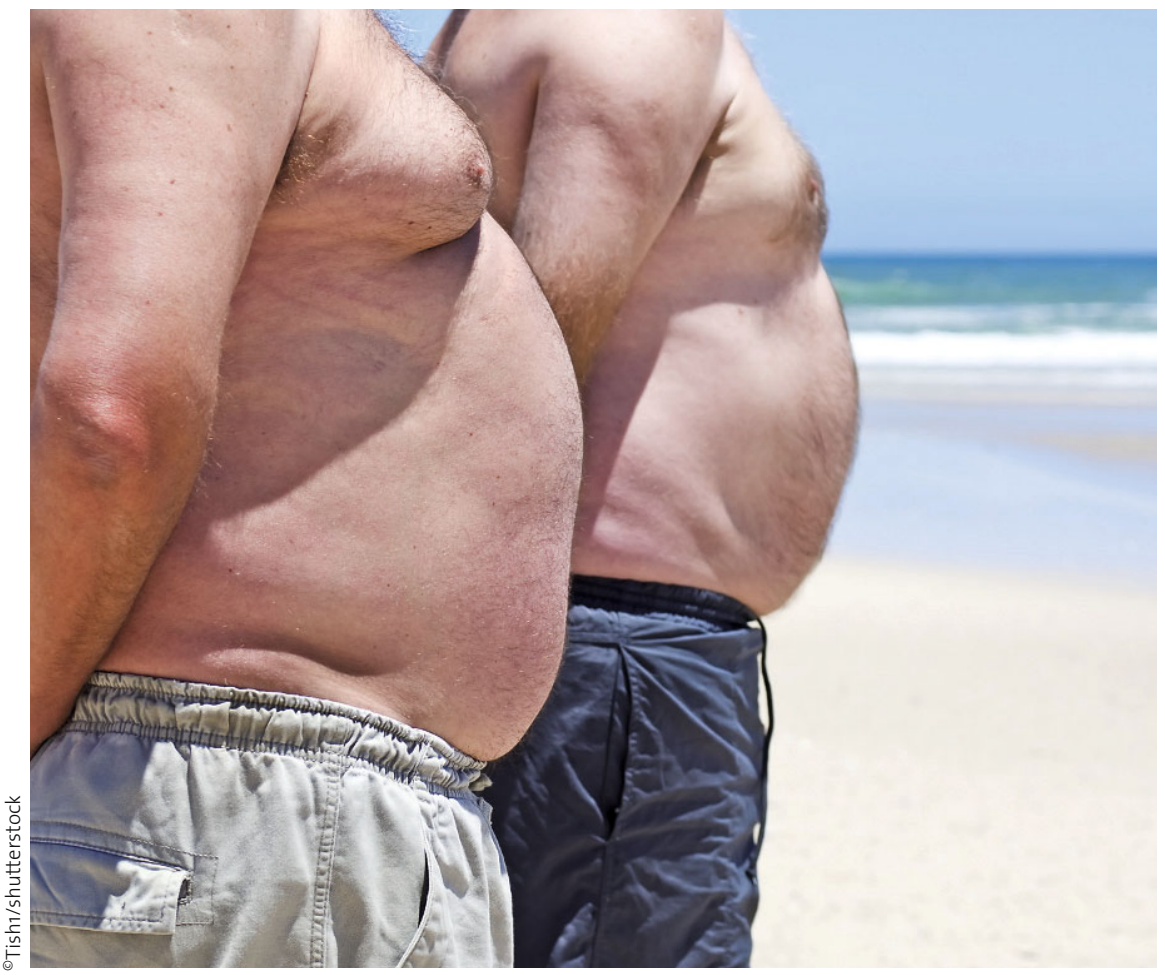

Orlistat wurde in einer Dosierung von $120 \mathrm{mg}$ dreimal täglich oral appliziert, Liraglutid einmal täglich subkutan injiziert. Allen Probanden wurde eine hypokalorische Diät mit einem kalorischen Defizit von $500 \mathrm{kcal} / \mathrm{Tag}$ verordnet, und alle bemühten sich, ihre körperliche Aktivität während der 20-Wochen dauernden Studie zu erhöhen. In den vier Dosierungen 1,2 mg, $1,8 \mathrm{mg}, 2,4 \mathrm{mg}$ und $3 \mathrm{mg}$ Liraglutid kam es dosisabhängig zu Gewichtsabnahmen von 4,8 kg, 5,5 kg, 6,3 kg und $7,2 \mathrm{~kg}$. Unter Placebo nahmen die Patienten $2,8 \mathrm{~kg}$ ab, unter Orlistat 4,1 kg.

$76 \%$ der Patienten unter der 3-mgLiraglutid-Dosis erlebten eine Gewichtsabnahme von mehr als 5\%. Unter Placebo bzw. Orlistat geschah dies nur bei 30\% bzw. 44\% der Probanden. Als wichtigste Nebenwirkung kam es unter Liraglutid zu Übelkeit und gelegentlichem Erbrechen. Diese Nebenwirkungen waren aber i.d.R. vorübergehend und führten bei nur ganz wenigen Probanden zur vorzeitigen Beendigung der Studie.

Kommentar

Die Ergebnisse der Gewichtsreduktion unter Liraglutid sind vielversprechend. Entscheidend wird sein, ob sich dieser Behandlungserfolg auch über einen längeren Zeitraum hinweg fortsetzen und stabilisieren lässt. Bis dahin werden nach wievor bariatrisch-chirurgische Abteilungen wie Pilze aus dem Boden schießen.

H. S. FÜEßL .

\footnotetext{
- A. Astrup et al.

(Korr.: Arne Astrup, Prof., Department of Human Nutrition, Faculty of Life Sciences, University of Copenhagen, Rolighedsvej 30 DK-1958, Frederiksberg, Denmark, e-mail: ast@life.ku.dk): Effects of liraglutide in the treatment of obesity: a randomised, doubleblind placebo-controlled study. Lancet 374 (2009) 9701, 1606-1616
}

Diät allein wird diese Konturen kaum in Form bringen. 